\title{
HOMENAJE A LOS PROFESORES MIGUEL AVILÉS Y MARÍA PALACIOS
}

\author{
José Fernández García
}

Universidad de Jaén 
El transcurrir del tiempo va introduciendo siempre sombras y olvidos en la mente de los humanos. Sombras y olvidos que quizás estén en relación inversa a los afectos y al impacto que, derivados del propio modo de ser de cada individuo, obran en los que han tenido contacto o relación en el pasado. Por ello cuando una persona reúne una serie de. características que lo hacen respetado y querido, el recuerdo agridulce, que va quedando en la nebulosidad del paso del tiempo, tarda más en desvanecerse. De ahí que no resulte fácil el escribir estas líneas cuando al evocar al profesor Miguel Avilés Fernández, parezca que su vitalidad derrochadora tan peculiar esté a punto de hacer aparecer la alta figura de inteligente mirada, con la plateada barba aparentemente descuidada, inmersa, a veces en la larga bufanda roja que a modo de beca, tras una pequeña vuelta alrededor del cuello, discurría por su pecho y espalda, e, inseparable al aspecto, la bien timbrada tonalidad de su voz al servicio de entrañable afabilidad, a la que, ni siquiera la firmeza sostenida, en determinados momentos del decir y del obrar, lograba disminuir, haciendo prevalecer un trato afectuoso, cortés y amable, que en él siempre parecía sencilio y espontáneo. Todo ello, aún, deja un poso de incredulidad, a su desaparición en sentimientos de las personas que tuvieron alguna relación con él, aun cuando la lógica de la razón le incluya irremediablemente en el pasado.

Compartí con Miguel momentos importantes. Momentos que se remontan desde la infancia hasta los últimos instantes de su paso por este mundo; con bastantes cosas en común, realizando y soñando proyectos que la identidad de nuestros enfoques vitales había traducido en objetivos coincidentes hacia una profesión que sirvió para estrechar, más aún si cabe, los entrañables lazos familiares y de amistad que nos unían. $Y$ aunque, frente a mi sedentarismo opusiera su ajetreada existencia, fruto de la insaciable inquietud y de un, en apariencia, paradójico espíritu aventurero y científico, siempre lograba que ni la distancia ni el tiempo introdujeran elementos distorsionadores en la realidad afectiva que nos profesábamos.

Su excepcional trayectoria sirvió, aunque nuestras edades fueran similares, entre otras muchas cosas para hacerme discípulo suyo, deudor 
de su generoso magisterio y colaborador en los últimos tiempos en algunos de sus ilusionantes proyectos.

Jaén marcó a Miguel Avilés. Aquí nació y en las tierras de esta provincia murió. Sus momentos más importantes, sin desdoro de su proyección nacional e internacional, los pasó en Jaén. El que iba a ser su gran proyecto, la creación de la Biblioteca Internacional del Renacimiento, afectaba a estas tierras, ricas en frutos y azares. Desde las cátedras que ocupó siempre hubo un hilo con «su» Jaén, mantenido en la proyección bien de actividades docentes o culturales, o bien, desde la perspectiva de la gestión. Era jienense por los cuatro costados no sólo en la presunción, sino, además, en el hacer. Pertenecía a la pléyade de las ansiadas figuras que esta tierra siempre quiere recuperar para configurar un futuro mejor que destierre la secular postración, protagonista, desde hace siglos, de su Historia.

Miguel Avilés nació el 17 de enero de 1940, en el seno de una arraigada familia de Jaén. Precisamente en una fecha, día de San Antón, celebrada especialmente en esta ciudad, con luminarias encendidas por todos los barrios y a su alrededor los típicos «melenchones», testimonios reales de la sencillez de un pueblo, sensible, entre otras cosas, a apreciar el valor de la amistad y la buena relación entre los seres humanos. Ese poder de comunicación y relación impregnó a Miguel y dejó su impronta como ponen de manifiesto todas aquellas personas que le trataron o le conocieron.

Infancia y adolescencia transcurrieron en la capital andaluza, en los difíciles años de la postguerra en los que las carencias de todo tipo eran enormes, siendo el objetivo fundamental, para la mayoría de los jienenses, la subsistencia, por lo que las inquietudes culturales e intelectuales quedaban relegadas, prácticamente, a algunos colegios de primeras letras; un Instituto de Bachillerato para toda la provincia, un Seminario Conciliar de Estudios Eclesiásticos y una Escuela Normal para el ejercicio de la muy abnegada, siempre, profesión del Magisterio. Así pues, poca variedad ofertaba a la ciudad para satisfacer inquietudes de cualquier tipo. $Y$ todo ello con la complicación de las secuelas, en esta provincia importante, que la Contienda Civil había dejado y de las que tardaría bastante tiempo en recuperarse, marcando a casi todos sus habitantes de un modo u otro.

Sin embargo, en este panorama, Miguel destacó en los estudios y recuerdo cómo en los cálidos veranos en los que los familiares hacíamos más frecuente nuestra relación, sus padres orgullososo del hijo, enumeraban y alababan sus esfuerzos en el estudio, en el que obtenía las más altas calificaciones. 
Desde que empezó a cursar los estudios medios llamó la atención de profesores y condiscípulos por la claridad de ideas, la facilidad en la exposición y su enorme capacidad de trabajo, avalada por las largas horas de estudio. La gran cantidad de compañeros y amigos, que le añoran en el recuerdo, pueden testimoniar estas afirmaciones. Jaén, Santander, Alemania e Italia fueron lugares donde Miguel se formó. La discontinuidad de las becas recibidas en la difícil coyuntura de los años cincuenta en el que muchos organismos públicos no se distinguían, precisamente, por mantener con la constancia deseada las ayudas al estudio, hicieron que Miguel Avilés, entre la concesión de unas y otras, impartiera docencia en algunos centros públicos de la provincia jienense en cursos escolares diferentes. Quizás donde más huella dejó fue en la Escuela Normal de Maestros en la que, todavía profesores actuales y discípulos esparcidos por todo el ámbito provincial recuerdan sus brillantes exposiciones y el afectuoso trato con el que distinguía a todos aquellos que con él se relacionaban. Fueron los años de magros estipendios en todos los niveles de la docencia que obligaban al recurso del pluriempleo por necesidad, y no para adquirir mayores cotas de comodidad. La generación de la postguerra conoce aquellos difíciles años en los que se exigieron esfuerzos desproporcionados a las remuneraciones estipuladas. Ello como contrapartida ofrecía la áscesis de una reciedumbre en la formación de caracteres al margen de la sociedad de consumo que antepone e intenta el bienestar por encima de todo. Así pues, a las características antes apuntadas de Miguei Avilés se unieron las específicas de esta etapa en la historia de dificultades que se vivieron hasta bien entrada la década de los sesenta, en la que los esfuerzos y sacrificios de mayor parte del pueblo español, procuraron unas sólidas bases en las que se asentaría el gran desarrollo posterior de nuestra comunidad nacional.

Fue, precisamente, en aquella década cuando Miguel movido por sus inquietudes marchó a Roma con una vocación que no acababa de estar definida debido, en gran parte, a las variadas opciones aptitudinales que en él se maniíestaban, hasta entonces sólo centradas en su inclinación al estudio, en su alteridad en el trato humano y en su facilidad expositiva. Todo ello valía para una gran variedad de ocupaciones u oficios. O si lo entendemos en otras palabras, todavía no había encontrado su auténtico perfil profesional. Sería en la Ciudad Eterna donde empezó a interesarse en las ciencias afines a la Historia. Con la sólida formación lingüística adquirida, en años anteriores, del alemán, francés e italiano, se interesó, en unos primeros momentos de la estancia en Italia, por el mundo de la Arqueología obteniendo en el año 1968 la Diplomatura en Arqueología Cristiana por el «Pontificium Institutum Archaeologiae Christianae» de Roma. No es, pues, de extrañar que antes de dedicarse a lo que sería 
su obra fundamental realizara, fruto de aquellas primeras aficiones, algunos trabajos relacionados con los primeros estadios culturales del hombre.

Al año siguiente a aquel de la adquisición de la Diplomatura en Arqueología Cristiana, obtuvo la Diplomatura en Archivística por la "Scuola di Archivisticas de Roma y la Licenciatura en Historia de la Iglesia por la Universidad Gregoriana de Roma con las máximas calificaciones posibles. Ello supuso para Miguel Avilés la delimitación de gran parte de la orientación futura de sus trabajos históricos. Este mismo año fue nombrado Colaborador de Investigación del Instituto "Enrique Flores» del Consejo Superior de Investigaciones Científicas.

En 1970 se trasladó a Madrid licenciándose en Filosofía y Letras, en la ya desaparecida sección de "Geografía e Historia», por la Universidad Complutense de Madrid, convirtiéndose a pesar de sus máximas calificaciones, en otro de los innumerables licenciados que había de enfrentarse con las enormes dificultades que suponía hacerse con un puesto de trabajo. La fortuna deparó que alguien hablara a la familia Garrigues de su brillantez y, aquélla le encargó la ordenación de su biblioteca y documentación, tarea que, anteriormente, había sido enconmendada a diferentes personas sin que, por las dificultades de catalogación y ordenación, hubieran tenido éxito. Miguel salvó todos los escollos y el trabajo realizado, en un tiempo inverosimil, sirvió para que su ocasional empresario, hombre con bastantes influencias, le buscase el que le nombraran para una vacante de profesor ayudante de clases prácticas en la Facultad de Filosofía y Letras de la Computense. A los pocos días, gracias a una coyuntura favorable, por desdoblamiento de grupos, su contrato administrativo cambió, pasando a la categoría de profesor adjunto interino con dedicación plena en la Universidad Autónoma de Madrid en la que se mantendría desde octubre de 1970 hasta mayo de 1974, con el exiguo sueldo que, hoy, cualquier joven profesor puede imaginar y que condenaba a estrecheces y dificultades de tido tipo, característica común para los que decidian iniciar la carrera docente universitaria. A pesar de ello, las exigencias, por parte de los equipos de gobierno de las universidades, departamentos o secciones, eran muy grandes y a las plazas de interinidad se accedía tras rigurosa valoración de los curricula, seleccionando los expedientes más brillantes y salvando la competitividad que en nuestra profesión suele ser muy numerosa. Entre los méritos aducidos por el entonces recién licenciado estuvo el de becario de fondo de formación del personal investigador a propuesta de la Comisión de Investigación de la Universidad Complutense y de la Comisión Nacional que mantuvo en el trienio de 1970 a 1973. 
Ocurrió durante el período de interinidad que, con motivo de la proclamación del entonces príncipe Juan Carlos como heredero de la Corona Española, éste, en una recepción, al ser preguntado por los propietarios argentinos de la Editorial Edaf, qué era lo que ellos podían hacer para agradar al príncipe, que éste les respondió que una buena Historia de España. La petición no cayó en olvido y los editores buscaron para la dirección de la obra a la persona que consideraron más idónea para la ardua labor a encomendar: Miguel Avilés. En la realización de esta magna empresa aparte de su gran capacidad historiográfica, manifestada en los diferentes capítulos que él realizó como profesional, puso de manifiesto otras cualidades que, posteriormente, seguiría desarrollando, como fueron: sus datos de organizador que le permitieron rodearse de inestimables colaboradores y concluir la edición en un tiempo récord, sin que la bondad del trabajo se resintiera por las premuras, y la fructífera etapa de relación, no, solamente, con la Editorial autora del proyecto, sino, además, con otras casas editoriales e instituciones del país, que le servirían en el futuro para desenvolverse en el complejo mundo de las editoriales, presidido por intereses crematísticos, que dificultan, en bastantes casos, la publicación de las obras científicas. No obstante, los responsables de la Editorial Edaf apreciaron, desde los primeros momentos, el trabajo y la capacidad de Miguel Avilés, que no quedó tan sólo limitado a la redacción de temas históricos y de dirección de obras colectivas, sino, además, al asesoramiento editorial y supervisión de colecciones y obras relacionadas con la Historia Universal y con la Filosofía, con lo que se ponían de manifiesto otra serie de aptitudes basadas en una gran formación multidisciplinar que garantizaba la calidad de las empresas en las que tomaba parte.

En el cuatrienio anterior a 1974 Miguel Avilés tuvo, pues, una intensa labor que no se circunscribió a su labor docente en la Universidad Autónoma y a la realización de la Nueva Historia de España, que vio la luz en 1973, sino, también, a la realización de labores de investigación que culminaron con la defensa de su Tesis Doctoral, en octubre de 1974.

La obtención del Título de Doctor supone, en la tarea universitaria, el plácet para aspirar a puestos superiores en el denominado escalafón administratitivo, ya que es el culmen del académico. Si en éste, cada cual puede controlarlo, periodizarlo y dirigirlo, sin excesivos lastres o dificultades, la promoción en aquél supone la adaptación a otros factores y condicionantes que escapan al protagonista que no suele, casi en ningún caso, poder decidir el momento más idóneo para tratar de ascender en el mismo escalafón.

Así pues, el profesor Miguel Avilés hubo de esperar otros cuatro años para conseguir la estabilidad que las oposiciones a profesor numerario 
deparan, logrando el pase desde la situación de profesor agregado interino, que ejerció desde octubre de 1974 a junio de 1978, a la de profesor adjunto numerario con dedicación exclusiva que ya le permitía entregarse por completo a las correspondientes tareas docentes e investigadoras. De otro lado, su perfil dentro de la profesión se había ido delimitando. Si antaño, hasta el año 1972, su actividad docente se centraba en la Prehistoria e Historia Antigua, a partir del año 1973 su cualificación y vocación derivarian hacia la Historia Moderna en la que pronto iba a destacar como un consumado especialista e investigador.

La carrera administrativa del profesor Avilés llama poderosamente la atención a partir de la adquisición de su condición de numerario, pues, conseguida la tranquilidad suficiente que ello supuso, incrementó la labor investigadora y su ritmo de trabajo. Todo ello sin detrimento de la atención a su familia, discípulos, y a los compromisos de gestión, por los que todo profesor universitario debería de pasar, pues, aparte del enriquecimiento personal que puede suponer, significan, en muchos casos, la conformación de actividades mentales y hábitos que, posteriormente, al abandonarse el cargo directivo, garantizan la comprensión y la participación en decisiones, que en muchos casos, aunque impopulares, son necesarias, pero que, de cualquier modo, sitúan al profesor universitario en condiciones para la asunción de determinadas responsabilidades que se pueden extrapolar a otros círculos sociales. Tras la consecución de la Adjuntía, a los dos años, concretamente en julio de 1980, ganaba, tras brillante oposición, la Agregaduría de la Universidad de Cantabria, culminando en el mismo mes del año siguiente, su trayectoria profesional al obtener la Cátedra en la Universidad de Córdoba. Es curioso observar cómo su bien ganada fama de trabajador infatigable le precedía porque en el curso que estuvo ocupando la Agregaduría en la Universidad de Santander, ya fue incorporado al cargo académico de Vicedecano de la Facultad de Filosofía y Letras, a pesar de su recientísima incorporación.

En todo el período anterior el profesor Avilés no dejó de realizar publicaciones, aproximadamente una veintena, entre libros y capítulos de los mismos, participando con ponencias en numerosos congresos nacionales como el de Historia de Aridalucía, las ll Jornadas de Historia sobre la Reforma, el Symposium Internacional sobre la Inquisición Española, celebrado en Cuenca con motivo del $V$ Centenario de aquel evento... y, en otros internacionales, como el Symposio Interdisciplinario sobre la Inquisición Medieval y Moderna que tuvo como residencia la ciudad de Copenhague en 1978. En algunos de ellos coincidimos y, en todos, destacó no solamente desde el punto de vista profesional, por la profundidad e importancia de sus aportaciones, sino, además, por su facilidad de trato y relaciones, que le hizo muy pronto ser popular y querido por los nu- 
merosos congresistas y acompañantes que, ganados por su jovialidad y dinamismo, irradiaban hacia él auténticos sentimientos de amistad.

De otro lado y a pesar de la parquedad de sus residencias habituales, tanto en Madrid, Cantabria y Córdoba, numerosos discípulos pueden atestiguar su dedicación y atención, que le hacian centro de actividad incesante dirigiendo memorias de licenciatura y tesis doctorales con gran profusión.

El período más dilatado de su trayectoria profesional lo realizaría en Córdoba donde, ya, desde la Cátedra de Universidad, ejercería, además, otras actividades relacionadas con la tarea universitaria al margen de la docencia y la investigación.

Su incansable actividad le había hecho multiplicarse en tareas complementarias a las labores normales de cualquier profesor universitario destacándose en la Organización de Congresos y Exposiciones como es el caso de I Symposium Internacional sobre la Inquisición Española de 1978 que contó con gran cobertura por parte de innumerables medios de comunicación no sólo del país, sino, también, del extranjero. Poco tiempo antes había sido uno de los fundadores del Centro de Estudios Inquisitoriales, y su solvencia intelectual le había aupado a diferentes presidencias en determinadas asociaciones de los ámbitos universitarios estatal y supranacional como fue la Presidencia de su Asociación Nacional de Servicios de Publicaciones Universitarios y del Instituto Internacional de Historia de los Pueblos Mediterráneos, siendo reclamado, además, para formar parte de distintas comisiones técnicas oficiales de la Junta de Andalucía y del Ministerio de la Presidencia del Gobierno con el que colaboró en el Proyecto «Iglesia, Economía y Sociedad» propuesto a aquél por la Universidad Autónoma de Madrid en los ejercicios de 1976 y 1877 siendo directores del Proyecto los Drs. Joaquín Pérez Villanueva y Felipe Ruiz Martín.

Las aportaciones escritas de Miguel Avilés son numerosísimas, casi un centenar entre libros, capítulos de los mismos, ponencias, prólogos y artículos en revistas científicas. Todos ellos relacionados con sus actividades profesionales. Hay, sin embargo, una faceta menos conocida o mejor, conocida tan sólo por un reducido grupo de personas, que es la relativa a cierta "vena» lírica, de la que, en la actualidad, se ocupa el profesor Dámaso Chicharro que ha recogido y está analizando la producción inédita, en la que se puede apreciar la gran sensibilidad e ingenio de un Miguel Avilés que, en la más profunda intimidad, se nos presenta con matices de honda ternura, timidez impensada y pulcritud estilista. Pero volviendo al campo profesional hay que señalar que su producción histórica escrita, fuera de los trabajos de recensión en los que en todos se 
puede apreciar la aportación personal derivada de la profunda reflexión tras los contrastes en las fuentes utilizadas, en el ámbito de la investigación, los orientó, fundamentalmente, en torno a la Historia de las Infraestructuras ideológicas en la Edad Moderna, atendiendo especialmente a cuatro campos:

a) Historia de los movimientos espirituales, centrados, la mayor parte de los que aparecieron durante el siglo XVI, en distintas órdenes religiosas $y$ en variados puntos de la geografía nacional sin descartar alguno que rebasa nuestras fronteras.

b) Historia de la Inquisición. En esta línea de investigación, quizás, en la que el profesor Avilés se sintiera más a gusto, es la de mayor número de títulos y de los más variados enfoques aun en la misma temática: legislación, filosofía, organización, personajes, fuentes, etc., son objeto de profundo estudio en distintos espacios y en el transcurso del tiempo en el que aquella institución estuvo en vigor. Su autoridad, en este campo, fue tan patente que desde todos los lugares donde el alto Tribunal ha sido estudiado, su presencia o sus aportaciones, fueron reclamadas. $Y$, al igual que hemos señalado para el apartado anterior, su obra desbordó los limites nacionales para extenderse por los diferentes centros de estudio que en el ámbito internacional se interesaron por el Tribunal Inquisitorial.

c) Historia de la llustración. También este periodo fue objeto de atención por parte del profesor Avilés. Y aquí se produjo el feliz encuentro de la curiosidad por el apasionante fenómeno histórico y la recuperación de un campo relacionado con sus vivencias y afectos. Él, ya desde hacía varios años, venía interesándose por el hecho de la llustración que culminó con la publicación en 1983 de «Introducción, edición y notas a Pedro Rodríguez de Campomanes»y, sucedió que un grupo de entrañables amigos, relacionados todos con su origen en las Nuevas Poblaciones, decidieron organizar una serie de congresos relativos a dicha temática. Enterado Miguel Avilés, desde el primer momento, ofreció una entusiástica y valiosísima colaboración que se tradujo y aún continúa traduciéndose en unos encuentros bianuales que son modélicos en cuanto a organización y aportaciones históricas. Con gran placer y orgullo aceptó la Dirección Técnica de tales eventos y la ostentó hasta su infortunada desaparición.

d) Historia del Pensamiento utópico en la España Moderna. En esta línea también muestra variedad ampila aunque, a mi juicio, su primer título publicado en 1976, "Sinapía, una utopía española del siglo de las Luces» es el más trabajado y en el que la frescura del tratamiento del fenómeno utópico y su profundo análisis, llaman poderosamente la atención sobre 
la capacidad del autor. La utopía, consustancial a la esperanza en el ser humano, fue analizada por el profesor Miguel Avilés en los tres siglos de la Edad Moderna, en los que, junto a los sueños ficticios, contrapuso las luchas ideológicas para la plasmación real de unos modelos sociales que han intentado, en todos los tiempos, hacer al colectivo humano más justo y feliz.

Al margen de esta fecunda labor en su obra publicística, el profesor Avilés mantuvo una constante preocupación por la mejor formación de los estudiosos de la Historia Moderna como se puede apreciar en la publicación de 1985, desde su cátedra en la Universidad de Córdoba, de una «Bibliografía básica para el estudio de la Historia Moderna, Universal y de España», que, con la debida actualización, continúa siendo obligada referencia para todos aquellos que pretenden acercarse o profundizar en este período de la Humanidad.

La actividad del catedrático Miguel Avilés en Córdoba se puede calificar, en la década de los 80 , de frenética. Además de las consabidas tareas cotidianas de las obligaciones universitarias, ocupó diferentes puestos de responsabilidad en los distintos equipos del gobierno universitario que se sucedieron en la ciudad de los Califas. Así, fue director del Servicio de Publicaciones entre los años de 1982 a 1989 y director del Departamento de Historia Moderna, Contemporánea y de América durante los cursos de 1987 y 1988. Todo ello sin menoscabo de una intensísima actividad en gran parte de las universidades españolas y en otras de diferentes países como Italia, Dinamarca, Brasil, Hungría, Portugal, Estados Unidos..., actuando como conferenciante, ponente o presentando comunicaciones, esperadas desde el ámbito científico-histórico como gran expectación. Lo más liamativo, a mi juicio, en este período, junto a la enorme actividad emprendida que le transformaba en impenitente viajero era la acentuación de esa fresca y ocurrente jovialidad que le hacía granjearse, sin esfuerzo apenas, a todos aquellos que entraban en contacto con él. Poseía la rara habilidad de hacer lo difícil enormemente fácil, y no le detenían, cuando ideaba algún proyecto, ni los múltiples compromisos y ocupaciones, ni las dificultades burocráticas con las que hay que encontrarse si se intentan plasmar en realidades ideas innovadoras. Es por ello por lo que en 1984, fue investigador principal de dos proyectos de investigación: uno perteneciente al Programa Sectorial de Promoción General del Conocimiento del Ministerio de Educación y Ciencia, para ahondar en el Corpus Legislativo de la Inquisición Española, el otro, aprobado por la Consejería de Educación y Ciencia de la Junta de Andalucía, para el estudio del origen y la evolución del Tribunal Inquisitorial de Sevilla. 
A pesar de fijar su residencia en Córdoba, sus inquietudes no le hacian circunscribirse a los límites de esta Universidad. Él no consideró nunca como definitivo el destino en aquella ciudad y al aproximarse la década de los 90 ya había manifestado en la intimidad su deseo para seguir ampliando horizontes.

Tras profunda reflexión y contraste en el círculo familiar consideró que había llegado la hora de fijarse otras metas y a ello obedeció su presentación a la Cátedra de Historia Moderna de la UNED. Conseguida ésta, se abre lo que se puede considerar el último período del profesor Miguel Avilés.

Pronto el destino que muchas veces se determina como caprichoso iba a enlazar sus actividades con su vieja aspiración de regresar a la ansiada tierra de los plateados olivares, que antaño cantara Machado. Aquí conservaba casi todas sus raíces, familia, amigos...

La provincia de Jaén cuenta con el centro asociado de la UNED, en Úbeda, “Andrés de Vandelvira», que mantenía una extensión en la capital. Al ser uno de los patrones la Diputación Provincial, ésta es la que convoca la plaza de Director del Centro Asociado. Las diferencias entre el representante de aquel organismo y el director electo condujeron a una situación que, poco a poco, fue haciéndose insostenible hasta que, visto el deterioro, desde la sede central de la UNED, en Madrid, se decidió una intervención que pusiera fin a tal estado de cosas. La dimisión del entonces director, el doctor Aurelio Valladares, facilitó la nueva solución que pasaba por destacar a Miguel Avilés en comisión de servicio, como dirigente del Centro. Este remedio fue muy bien visto desde Madrid y desde Jaén, donde el profesor Avilés era bastante popular, pues, a las innumerables amistades que tenía, se unió el hecho de una participación activa desde sus diferentes destinos profesionales, asistiendo y organizando congresos en toda la provincia, dando conferencias reclamado por casi todas las instituciones existentes en Jaén e incluso como miembro activo de las distintas asociaciones culturales que hoy existen en la capital y provincia. Su infatigable actividad le había permitido no descuidar sus afectos y raíces a pesar de los numerosos viajes y ocupaciones.

Con dos problemas graves tenía que enfrentarse el nuevo director: por un lado el problema económico, consustancial, casi en todos los centros asociados que dependen de Diputaciones y Ayuntamientos, con la consiguiente y tradicional falta de liquidez que, en la mayoría de los casos, caracteriza a tales instituciones; de otro, con la ralentización experimentada por el desarrollo de unos estudios que habían ido deteriorándose por una serie de factores complejos en las que se mezclaban aspectos políticos, personales, económicos y profesionales y, en fin, una variada 
casuística que, inevitablemente, parecía conducir a la desaparición de las facilidades para el estudio a un sector de la población, que por sus peculiares características, reclamaba el tipo de enseñanza que la UNED venía ofreciendo.

El nuevo director mantuvo entrevistas con tutores, políticos, alumnos y otra serie de personas relacionadas más o menos directamente con el Centro Asociado y con la problemática de la Enseñanza a Distancia de la Provincia de Jaén. A los pocos meses los resultados conseguidos fueron espectaculares. Por primera vez, desde su establecimiento en Jaén, las remuneraciones de los profesores-tutores eran atendidas con puntualidad, se contrató un seguro para los docentes que tenían que trasladarse de una ciudad a otra, se resolvió el problema de ubicación de la subsede en la capital que habia venido siendo un handicap para la consolidación de algunas enseñanzas, se amplió la oferta de un mayor número de titulaciones, se firmaron acuerdos en otras localidades de la provincia jienense, para una mejor atención del alumnado, se establecieron las bases de un perfecto entendimiento entre la Institución patronal y los docentes, $y$, en fin, en los distintos centros de la UNED, en Jaén, comenzó a practicarse una febril actividad que ha marcado una época de serenidad y de desarrollo de la Enseñanza a Distancia, en esta provincia.

Miguel Avilés nos empujaba a todos. El Centro Asociado adquirió un gran prestigio y junto a las labores tutoriales-docentes se iniciaron otra serie de proyectos encaminados a ofrecer una complementaria actividad cultural y a estrechar los lazos entre los numerosos componentes que integran esta comunidad docente. La infatigable actividad y jovialidad del doctor Avilés le llevó a contar con el apoyo unánime de todos los implicados en esta tarea y ello fue apreciado por los diferentes medios de comunicación existentes en la provincia, los cuales se hicieron eco de las actividades del Centro asociado, redundado en que desde distintos municipios se reclamara la presencia de la UNED como complementaria de una enseñanza Universitaria presencial que la Universidad de Granada, con el Campus Universitario de Jaén, no llegaba a abarcar en su totalidad; y que, gracias al buen hacer del Director, se traducía en unas inmejorables relaciones entre ambas universidades.

En el tejido social jienense y en sus instituciones Miguel Avilés asentó aún más, si cabe, su popularidad. Sus ingeniosas respuestas en las que subyacían detalles de fino humor le hacían ser centro atractivo en todas las tertulias y reuniones a las que asistía. Recuerdo que en la última visita que los Monarcas españoles hicieron a Jaén, el Ayuntamiento y la Diputación Provincial les ofrecieron una recepción en el Castillo Parador de Santa Catalina que a modo de incansable centinela preside a la ciudad 
de Jaén. En el transcurso de la recepción y superados los momentos protocolarios, los asistentes se dispersaron formando corros entre los que, salvo alguna excepción, tenían los mismos intereses profesionales. Don Juan Carlos y doña Sofía iban departiendo con unos y otros de modo informal. Cuando el rey de España se acercó al grupo en que estaba Miguel Avilés, preguntó por la actividad en la que se ocupaban cada uno de los integrantes. Al enterarse de que eran docentes el Monarca, con naturalidad y sencillez, comenzó a contar algunos problemas que, como cualquier padre, le preocupaban de sus hijos y expuso las dudas de la infanta Elena, que en esos momentos, dudaba entre los estudios a seguir y la Universidad elegida por las interpretaciones o suspicacias que pudieran derivarse de inclinarse por alguna específica. Miguel Avilés sin pensárselo dos veces y visto el ambiente coloquial que el rey había creado, le sugirió que la infanta se decidiera por la que él consideraba la Universidad más democrática de todas. Sus palabras fueron: Majestad envíela a la Universidad mas «roja» del Estado Español que es la UNED. Un fugaz silencio se originó en el corro de personas, roto rápidamente por las carcajadas de don Juan Carlos que fue el primero en captar la broma, y en aclarar a los contertulios que el consejo estaba bien dado, puesto que, la UNED era la Universidad sin «clases».

La anécdota constituye, a mi entender, un pequeño botón de muestra de esa jovialidad inteligente y ese saber estar característicos del profesor Miguel Avilés. Junto a todo ello una gran firmeza a la hora de defender sus puntos de vista que no estaba reñida con la dialogante tolerancia del que sabe escuchar. Hasta el fatídico día que el mortal accidente segara la vida del matrimonio Avilés-Palacios, ambos, en una comunión intelectual, ejemplar para los que le rodeaban, tuvieron el mismo entusiasmo y entrega que antaño, y al inicio de sus prometedoras carreras, les había caracterizado.

Jaén, la UNED, la Historia Moderna, y, en fin, la Universidad española perdió una firmísima realidad, truncada cuando varios ilusionantes proyectos habían concitado las esperanzas de varios equipos de personas, todos los cuales giraban en torno a Miguel Avilés Fernández, inmejorable compañero e inolvidable maestro, a quien desde estas deshilvanadas cuartillas pretendo rendir homenaje de gratitud y afecto, en su recuerdo, con la completa certeza de que siempre estará presente en todos aquellos que le conocimos y admiramos.

En la memoria histórica permanece el hecho, unánimemente aceptado, de que las inmediatas generaciones, posteriores a la Guerra Civil Espa- 
ñola, vivieron tiempos en los que la principal preocupación constituyó la supervivencia ignorándose 0 , cuando menos, relegándose realidades, hoy muy presentes, que son objetivos fundamentales como bienestar, calidad de vida, etc.

En la escala de valores, impuesta a los españoles y aceptada con mayor o menor agrado, se primaban, entre otros, la bondad y necesidad del trabajo, la resignación, el conformismo, el orden a cualquier precio y algunos más que, según los ideólogos del bando triunfador, eran los adecuados para el momento histórico que se vivía. Por supuesto que dichos valores procuraban adaptarse a las diferencias humanas basadas en el sexo, la edad, tradición, etc.

El papel de la mujer, circunscrito al que había desempeñado tradicionalmente, se orientaba, con clara y nítida preferencia, a la dedicación al hogar y al cuidado de los hijos y el marido. Pretendíase, al igual que en otros aspectos, ignorar el denodado esfuerzo que muchas mujeres habían o estaban realizando en pro de la igualdad de derechos entre ambos sexos. Es cierto que por los momentos que vivían en España, tal reivindicación quedaba en un segundo plano limitada a minorías femeninas más o menos cualificadas, oficialistas o afines, con mayor o menor virulencia (nos inclinamos por la menor) y en pugna más pública o soterrada. Nuestras mujeres aspiraban (hoy todavía lo hacen) a situarse al mismo nivel y con los mismos derechos que los hombres. En el transcurrir del tiempo el aparato político del país tuvo que hacerse permeable a tales demandas y las mujeres de aquellas generaciones comenzaron a substraerse de sus específicas labores o compaginarlas con otras laborales que ellas y el proceso histórico evidente, en el entorno afín, exigían.

Así pues, con el paso de los años, en especial tras la Segunda Guerra Mundial, la aceleración, experimentada en los distintos campos del hacer humano, también estuvo presente en la lucha y conquista del mundo laboral por parte de las féminas. No obstante la sorprendente velocidad con la que se desarrollaron los acontecimientos sirvió para poner de manifiesto que la mayoría de las mujeres, que aspiraban a una pronta incorporación al mercado de trabajo, no se encontraban lo suficientemente preparadas para disputar a los hombres, en completa igualdad, los puestos de mayor responsabilidad.

Creo que estas apreciaciones las compartirán la mayor parte de las hembras y varones españoles por encima de los cuarenta años; y estimo que, además estarán de acuerdo en que si ya era penoso mejorar el "status» individual en los hombres, más difícil le era a la mujer (hoy todavía sucede) por la mentalización y el papel que, tradicionalmente, se le había reservado. 
En la complejidad del fenómeno subyacía una variada casuística motivada, en muchos casos, por la eterna aspiración de realizarse personalmente; en otros, por mejorar la calidad de vida en el plano individual o en el familiar, $y$, en unos pocos, por liberarse de ocupaciones que hacian verosímil el dicho de que «el trabajo de las amas de casa es tan difícil que ni siquiera las mujeres quieren hacerlo".

De cualquier modo la mujer, en la mayoría de las ocasiones, ha tenido o tiene que simultanear las específicas tareas del hogar con las laborales que son propias de los puestos que ocupan fuera de él. Ello es evidente en mujeres de determinada edad, nacidas entre los años de 1940 y 1960 , y se puede afirmar que, aplicado a ellas, es un hecho casi general, mientras que no ocurre así o, cuando menos, en la misma proporción, entre las generaciones posteriores.

Ruego al posible lector que sea indulgente con estas disgresiones con las que pretendo resaltar las grandes dificultades por las que han tenido que pasar la mayoría de las mujeres que han ocupado u ocupan puestos de trabajo y que, todavía, a pesar de sus esfuerzos no logran alcanzar la pretendida igualdad con los varones.

Prototipo común de mujer de la clase media española fue María Palacios Alcalde, jienense de conocida familia, hondamente enraizada en estas tierras. Le tocó vivir los tiempos difíciles, antes aludidos, en momentos importantes e innovadores para las mujeres que pasaron mayores niveles de protagonismo a partir de la demanda generada por las exigencias socioeconómicas de un país que tuvo que adaptarse a los nuevos modelos reclamados por la realidad de la comunidad internacional a la que por posición geográfica y tradición pertenecía.

Los limitados horizontes de la sociedad más inmediata de su entorno le hicieron acceder en un primer estadio, a los vocacionales estudios del Magisterio en la capital jienense, en donde, dicho sea de paso, eran los únicos por aquél entonces. Como tantas otras compañeras la elección se derivaba no sólo de una decisión personal sino, además, de la orientación familiar que veía en aquellos estudios la posibilidad de un futuro trabajo acorde, de un lado, con la mentalidad tradicional en el aspecto ocupacional propio de las mujeres, $y$, de otro, de la consideración y el pleno convencimiento de ser avanzadilla de una mayor consideración social de la mujer. En aquel tiempo, en Jaén, por el tradicional aislamiento, aún no había calado en las familias el enviar a las hijas a estudiar fuera de las fronteras provinciales.

En el año 1970 María Palacios concluyó con éxito los estudios de Profesorado de Educación General Básica. Sin embargo, las ilusiones y 
anhelos puestos en la consecución del título, los colocó en un segundo plano cuando hubo de optar, como tantas mujeres, en el tradicional dilema del trabajo fuera del hogar o en el realizado dentro.

Suele decirse que siempre tras el hombre triunfador existe una gran mujer. En el caso de María Palacios la reflexión es a la inversa o, mejor, complementaria. Su matrimonio con Miguel Avilés sirvió para que las inquietudes intelectuales que habían aparecido y cristalizado en aquellos estudios iniciales, tras los obligados paréntesis en exclusiva exigidos por la dedicación al hogar y a la crianza de sus hijos, volvieran a ser retomados buscando la identificación total con la persona que había elegido como compañero. Fueron años de intensa y doble actividad en los planos familiar e intelectual. María supo compaginar perfectamente ambos procurando el ingente esfuerzo de actuar como esposa, madre y estudiante de Filosofía y Letras, incorporándose, en este tiempo, como miembro del equipo de investigación encargado de realizar la catalogación y estudio del Archivo de la II República Española en el exilio, organizado por la Fundación Universitaria Española. Tal actividad no le impidió obtener la licenciatura en Historia con notable aprovechamiento. Es obvio que María había optado por el campo de la ciencia histórica, animada por Miguel, al que desde su matrimonio procuraba acompañar en los eventos en los que éste intervenía, siempre que lo permitían las obligaciones familiares. Así fue como participó en el I Congreso de Historia de Andalucía, en el año 1976, y quizá ahí tomó la decisión de optar por el estudio y la investigación de la Historia.

El fijar el matrimonio Avilés-Palacios la residencia en Córdoba permitió que la proximidad entre esta ciudad y Jaén, cuna de ambos, sirviera para que con frecuencia retomaran el trato familiar frecuente con los allegados que, en los últimos tiempos, desde el inicio de matrimonio, había quedado un tanto relegado y cuya causa estuvo en los avatares del destino que les había hecho residir, en los primeros tiempos, en Madrid.

En el período que hubo entre el termino de los estudios de licenciatura y la lectura de la Tesina, que le permitió a María la adquisición del grado de Licenciado por la Universidad de Granada con la máxima calificación, en el año 1985, ejerció actividad docente como profesora-colaboradora de la Cátedra de Historia Moderna de la Universidad de Córdoba, no sólo en el ejercicio diario sino, además, en el Curso de Archivista del año 1984 y en los II y III cursos de verano propiciados por aquella Universidad. En todos ellos destacó invistiendo la labor docente de ilusión, laboriosidad y acogedora humanidad que aún recuerdan sus alumnos. Estas actividades las compaginó perfectamente con la asistencia a Congresos Científicos como el I Congreso Histórico sobre "Las Nuevas Poblaciones» de 
Carlos III en Sierra Morena y Andalucía celebrado en marzo de 1983 en La Carolina (Jaén), el Congreso de Historia de Burgos, organizado por la Consejería de Cultura de Castilla-León en 1984, el Symposium «Inquisición y Poderes Políticos", en el mismo año, y algunos otros celebrados en diferentes puntos de la geografía española. También, y durante el mismo período, fue colaboradora en las obras «Epistolario de $\mathrm{P}$. Rodríguez de Campomanes» y en la "Historia de la Inquisición de España y América», ambos editados en Madrid, en los años 1983 y 1984, respectivamente.

Por estos años la metodología en algunas ciencias recibió aportaciones y aplicaciones de otras esferas del saber humano y, concretamente, en el campo histórico, se fomentó la utilización de equipos novedosos técnicos. Ello hizo que muchos profesores e investigadores intentáramos incorporarnos a la nueva "moda». María Palacios optó por esta vía y fue Becaria del Consejo Superior de Investigaciones Científicas en el curso "Aplicación de la Informática a la Investigación Histórica», y, además, participó como investigadora adscrita al Departamento de Historia Moderna de la Universidad de Córdoba, en el Programa Sectorial de Promoción General del Conocimiento del Ministerio de Educación y Ciencia en 1985. Además, en ese mismo año y el siguiente, ejerció de profesora en cursos para estudiantes de Cultura Española organizados conjuntamente por el Departament of Spanish and Latin American Studies del University College de Londres y la Universidad Cordobesa.

Los años transcurridos desde la adquisición del grado de licenciado hasta el doctorado en Historia Moderna y Contemporánea, en 1988, fueron los de su mayor actividad, pues registramos, en su dedicación a la docencia, el nombramiento para el curso 1986-87 de profesora-tutora de la Universidad de Educación a Distancia y, en 1988, el de profesora interina de la misma Universidad participando, en tal calidad, en los cursos de Verano «Antonio Machado» de la Universidad de Granada, amén de su adscripción como investigadora al Programa de Investigación de la Consejería de Educación y Ciencia de la Junta de Andalucía y de asistir con numerosas ponencias a los diferentes congresos a nivel nacional e internacional, celebrados por distintas universidades españolas y extranjeras, de todos aquellos temas que consideró fundamentales para un período personal que ya no era tan sólo formativo sino que se convirtió en palpable realidad profesional que auguraba el éxito.

Todo lo anterior lo hemos englobado tratando de exponer las bases de su sólida formación para la actividad docente en la que la actualización sirve de un complemento, absolutamente imprescindible, para una enseñanza moderna y eficaz. $Y$, aunque hemos esbozado, de un modo incipiente, algunos aspectos relacionados con la actividad investigadora de 
María Palacios, es hora que nos detengamos en ella porque, a mi juicio, constituye su labor más fecunda y creativa, quedando plasmada en las más de 40 publicaciones realizadas y que sirven para una justa interpretación de su talla intelectual.

Sus trabajos de investigación los orientó, fundamentalmente, hacia la Historia Social de las Mentalidades en la Edad Moderna. Dentro de ella distinguimos cuatro importantes aspectos:

A) La historia de la condición femenina en la Edad Moderna. A través de ella María publicó una serie de trabajos en los que abordó el problema de la marginación, el trabajo, creencias, modos de vida y los modelos ideales de mujer que algunos hombres idearon en el Renacimiento español.

B) La historia del control ideológico (Inquisición). Sus trabajos abordaron asuntos relacionados con los delitos perseguidos por el Tribunal Inquisitorial, modos de actuación, reacciones entre la población, el impacto sobre los colectivos religiosos moriscos, etc.; la legislación inquisitorial y otros temas relacionados con tal temática. En esta línea de investigación desbordó el ámbito jurisdiccional del Tribunal Inquisitorial cordobés realizando aportaciones de carácter general aplicable a la institución en su conjunto.

C) Ilustración, Sociedad e Iglesia. Objeto de análisis, estudio y difusión fueron distintos trabajos referidos a estas temáticas. En ellos el fenómeno más abordado fue el de las "Nuevas Poblaciones» centrándose en personajes que tuvieron un gran protagonismo, y en otros aspectos en los que la Sociedad y la Iglesia, íntimamente unidas, en el sigloxvIII, sirven para profundizar en su conocimiento.

D) Masonería. En este tema publicó en el diario "Córdoba" cuatro artículos, durante 1988, desvelando las claves de la masonería y divulgando todos los aspectos relacionados con la secta que llega hasta nuestros días.

De entre todo este amplísimo trabajo quiero destacar lo que a mi juicio constituye la aportación fundamental de María Palacios a la Historia de España. Es su obra "La Legislación Inquisitorial (1478-1504)», aún en microfichas, puesto que se encontraba en trámites de ser publicada cuando sobrevino el infausto y desgraciado accidente que hizo perder a la Historia Moderna dos excepcionales personas y dos realidades en el ámbito intelectual de nuestro país. Cuando, el 5 de diciembre de 1991, tuvimos la desgracia de perder a Miguel y María, en acto de servicio, quiso la Comisión Organizadora del Congreso del IV Centenario de la muerte de San Juan de la Cruz, de la que formé parte, rendirles homenaje con la lectura 
de los dos trabajos que el matrimonio había preparado para el acontecimiento. El que María Palacios presentó «Espirituales y Universitarios en la ciudad de Baeza en el siglo XVI", al igual que el de su esposo, fueron de difícil lectura por cuanto la emoción de los presentes se hizo más patente en los lectores que suplían a los autores y hubo que superar el hecho anímico con evidente esfuerzo.

Aún hoy, tercer aniversario de aquel episodio desgraciado, evocamos a María, con su bella y agradable fisonomía, rostro algo ovalado, talante acogedor y discreto, impregnado de gran actividad, y matizado por una imperceptible aura de tristeza inteligente y sutil sonrisa, siempre apuntada o predispuesta en ella. Su hermosa alegría, tocada por el ángel afable de la ironía que procedía del escrutinio inteligente y comprensivo del mundo, servía para adelantarse a cualquier intervención, especialmente si se trataba de algo grave. María, a mi juicio, en su expresivo rostro y actividad vital, puede servir de símbolo a las mujeres que creen, que hacen y que dudan. Titulaba Samuel Beckett a una de sus obras "No puedo seguir, seguiré» y ello a mi juicio es el epílogo ideal para María, pues, su recuerdo nos invita a ello porque identifica a una gran mujer cuya ejecutoria es ejemplar. 